\title{
A View on Reshaping of Entrepreneurial Spirit under New Economic Normal State
}

\author{
Jun-hua Liao \\ Tourism and Aviation Service College \\ Guizhou Minzu University \\ Guiyang, Guizhou, China, 550025 \\ E-mail:junhualiao0321@126.com
}

\begin{abstract}
Entrepreneur is the most strategic resource in all factors of production. It is of great significance in the development of enterprises, and entrepreneurship is a prominent reflects of the entrepreneur quality. Entrepreneurship acts out as innovation, adventure and keeping making progress, and its meaning is constantly evolving. The new economic normality put forward new requirements to our entrepreneurs, and also created a historic opportunity for entrepreneurs' grand plans. The majority of entrepreneurs should deeply understand the new economic normality, and actively adapt to the new economic normality, enhance the sense of mission and responsibility, put forward the spiritual innovation, and make efforts to promote innovation and the development of enterprises. At present, Chinese entrepreneurs should abandon the seeking awareness, have courage, work hard, be brave, and reshape the spirit of innovation and spirit of the contract.
\end{abstract}

Keywords-New Economic; Normal State; Entrepreneurship; Reshaping

Entrepreneur is the most strategic resource in all factors of production, and plays an important role in the development of enterprises. With the development of industrialization and the establishment and improvement of the modern enterprise system, the role of the entrepreneur is becoming more and more prominent. With the acceleration of global economic integration and the practice of "people-oriented" business philosophy, the status and role of entrepreneurs have been rising, and become the core competitive power of the enterprises. According to the experience of economic development of the developed countries, the high-quality entrepreneurs are closely related to the economic growth. Therefore, entrepreneurs are the main contributors to the economic growth. High-quality entrepreneurs are the guarantee of the economic growth, and the most important indicator to measure the quality of entrepreneurs is the spirit of entrepreneurship. In 2014, central economic work conference pointed out that the key of China's economic development is to understand the new normality and adapt to the new normality in the current and future period. The new normality means that economic development is facing the new environment and new conditions. We should assess the situation, follow the new logic, use new ideas and models to develop the economy. Under the new normality, if the lack of awareness of innovation, innovative ideas and the development of new methods, enterprises will be difficult or even eliminated by the market. As the soft power and core competitiveness of the enterprise development, entrepreneurs must adapt to the new normality, and create new entrepreneurial spirit.

\section{THE DEFINITION OF ENTREPRENEURSHIP}

Entrepreneurship can be traced back to the beginning of economic discipline, but its definition has not yet reached an agreement. Richard Cantillon, a French economist, thinks that the aggregation of special skills (including spirit, skill, etc.) is the spirit of entrepreneurship. [1]Joseph Alois Schumpeter pointed out that the entrepreneurial spirit is the internal psychological awareness to drive and stimulate the entrepreneur's ability to innovate and other capabilities, is the soul of entrepreneurs. [2] Marshall believes that entrepreneurship is a kind of psychological characteristics, which outstandingly embodies as the strong initiative and the strong desire to succeed. The specific performances are in three aspects: first, the entrepreneurs have strong selfrealization demands and not dissatisfied with present condition; second, the entrepreneur constantly innovating the realization way of value; third, they have strong sense of purpose and vision, professional dedication. [3] Domestic scholars have conducted effective researches on the entrepreneurial spirit, such as Feng Sining (2013) believes that entrepreneurship is an abstract expression of entrepreneurial talent quality, value orientation, business philosophy, courage and charm, such as the mode of thinking, which affects management behavior of entrepreneurs and it is the power source of the sustained and healthy development of enterprise.[4] Wang Jingjing (2014) pointed out that a series of behavioral characteristic entrepreneurs such as opportunity recognition, innovation, risk-taking, break the resource constraints and so on, which is displayed when entrepreneur use business knowledge to create social value, which is the external performance of entrepreneurship.[5]

From the above study, it is clear that the entrepreneur's spirit of adventure and the characteristics of uncertainty undertaker is the focus of most scholars. Entrepreneurs can effectively break the imbalance of the development of the market, and dare to take risks. Due to the complexity and instability of the market environment, the business activities are high risky, accelerating globalization adds to the business risk, it is necessary for enterprises to have adventurous spirit and risk consciousness to cope the risk.In the aspect of risk 
taking, the general managers only bear the risk of local and small degree, while the entrepreneurs often bear the overall risk and systematical risk. Drucker and Peter positions innovation as the core of entrepreneurship. Entrepreneurs destruct the market equilibrium creatively and the spirit of innovation is presented in three aspects: (1) to improve resource output; (2) to create new value; (3) to develop new markets.

Based on previous research results, the entrepreneurial spirit is defined as: the entrepreneur's way of expression in the comprehensive management of enterprises, is the soul of the entrepreneur, covering the enterprising spirit and innovation spirit, the spirit of the contract, the spirit of honesty, professionalism, dedication spirit and national spirit, which is intangible, personalized and causes fuzzy attributes. There are many spirits in the spirit of entrepreneurship, which is difficult to describe by a single feature. With the development of economic globalization, the diversification of people's values and the conflict and integration of various cultures, the connotation of entrepreneurship will continue to change.

\section{EPOCHAL SigNIFICANCE OF CARRYING FORWARD THE SPIRIT OF ENTREPRENEURSHIP UNDER THE NEW NORMALITY}

Due to the weak global economic growth, the post financial crisis and the impact of macroeconomic policies, China's economy has entered a stage of relatively low growth, and this feature will be maintained for a long time. GDP growth in the third quarter of 2015 for the first time fell below $7 \%$ and lowed to $6.9 \%$, which is the lowest level since 2010, and reflects the basic situation of China's economy. According to the central bank's estimate, China's economic growth will remain between $6.5 \%-7 \%$ level in the "13th Five-Year" period. Thus, the most direct manifestation of the new normality is economic slowing down. For a long period of time, many contradictions that has been overshadowed by China's rapid economic growth will blowout in the short term, with the result of the difficult situation for the domestic enterprises.

Two reasons lead to China's economy from rapid growth into slow growth: (1) At present, the basic conditions of our country to realize the economic growth (relying on the labor cost advantage, the demographic dividend and the input of production factors) have gradually lost; (2) The global economic recession caused the lack of effective demand. Therefore, the primary task of the new normality is to change the mode of economic growth and achieve economic transformation and upgrading. In the manufacturing sector, for example, except high-speed rail, nuclear power, other industries, the overall level is low (of low-end and low valueadded linkin the global industrial value chain). In 2014, China had more than 10 trillion U.S. dollars of total GDP, but the high-tech industry output value was still low (less than 1/6), and foreign enterprises created a considerable portion of the output. In the long run, China's economic growth is facing the risk of middle-income trap. Middle income trap is the macro level economic prosperity and recession cycles, the overall economic growth stalled, lack of motivation, and macroeconomic policies failed to stimulate the enterprise microcosmic failure; the lack of innovation, a new growth point is not found, the business is in equilibrium. Under the new economic normality, economic growth is driven by innovation, and the key to the innovation is to stimulate the entrepreneurial spirit. In addition, the current market environment of Chinese enterprises is not optimistic, lack of integrity and moral dislocation seriously affect the sustained and healthy development of enterprises, which is an important obstacle of entrepreneurs. Therefore, China's economic growth to cross the middle-income trap, in addition to the government's efforts to establish a fair and just rule of law in accordance with the market environment, which is more important to recast entrepreneurs spirit.

In 2014, the Chinese government put forward a new concept of governance--"new normality". The new concept of the new economy is closely related to the problem of the transformation of the mode of economic growth, the core task of the new normal is to change the mode of economic growth. At the beginning of 1980s, China proposed to change the mode of economic growth, but until today, China's economic growth mode is still the traditional mode of growth (high energy consumption, low efficiency) to a large extent. "What is the target growth pattern" and "how to realize the transformation of the economic growth mode" are the key problems to be solved urgently. The decision of the CPC Central Committee on deepening the reform of the overall number of major issues in the third Plenary Session of the 18th CPC Central Committee clearly stated that the allocation of resources should be determined by the market. Zhang Weiying and Sheng Bin pointed out that the process of reform is to some extent the process of entrepreneurship. [6] Therefore, Wang Cheng believes that the future of China's economic growth will be that the entrepreneurs become the choice subject and efficient use of production factors, while the original mode of production (government as the main body and the choice of overload cost of production resources) will no longer exist. The traditional economic adjustment policy tool seems to be inadequate, which is the fundamental reason why the whole society attaches great importance to entrepreneurship.[7]On the one hand, the Solow model of new classical economic growth theory holds that the key factor of economic growth is the material capital investment, but it has encountered the embarrassment of diminishing returns to capital in practice, capital driven growth has been proved to unable to maintain sustained economic growth.[8]On the other hand, the Romer model of new economic growth theory holds that the key factor of economic growth is investment in knowledge, however, in practice, policy tools such as education and government funding are also facing challenges. This phenomenon is largely due to the lack of entrepreneurial spirit between knowledge investment and innovation driven. Therefore, the entrepreneurial spirit is of epoch-making significance to the development of China's economy under the new normality.

\section{RESHAPING ENTREPRENEURIAL SPIRIT}

\section{A. Entrepreneurs should have the courage to struggle}

In the new situation, China's economic development is facing many new situations and new problems. In a critical period of transformation and upgrading, enterprise reform is at 
a crucial stage, so the entrepreneurs should further emancipate the mind, brave, dare to struggle, dare to play, and strive to achieve new development of enterprises under the new normality. Specific efforts should be made in the following areas: (1) Efforts to ensure stable economic growth. Under the new normality economy, China's economy is in a strategic period of development and structural adjustment, transformation and upgrading, the development potential is still huge. In view of the difficulties faced by the economic operation, the state has formulated a series of policies and measures to promote steady economic growth. In this difficult juncture, entrepreneurs should be firm confidence, work hard, the initiative to adapt to the new economic norm, promote innovation and development of enterprises to ensure stable economic growth. [9] (2) Dare to play, continue to boost enterprise reform. Under the new normality, state-owned enterprises should adapt to the new environment, vigorously develop the mixed ownership economy, actively absorb social capital and private capital, and enhance the vitality of enterprises. At the same time, private enterprises should actively participate in. In the process of developing the mixed ownership economy, it can promote the common development of state-owned enterprises and private enterprises. [9] (3) Considering the overall situation, take the initiative to integrate into the national development strategy (such as "One Belt One Road" strategy and the strategy of developing the western region, the Yangtze River Economic Area strategy etc.). At present, the national "One Belt One Road", the development of the western region, the Yangtze River Economic Area strategy for the development of Chinese enterprises has brought new opportunities, and the entrepreneurs should focus on the overall situation, take the initiative into the national development strategy, expand the space for the development of enterprises, and promote the sustained and healthy development of enterprises.

\section{B. Reshaping the entrepreneur innovation spirit}

Since the reform and opening up, China's economic development has created a miracle in the world, however, the entrepreneurial spirit did not improve with the expansion of the total economy and enterprise scale. Compared with the developed countries, it is in the low level, far below the expectations of society. In the current Chinese, there are many business leaders, speculators, the market balance master, but few of them can create market opportunities, adhere and attached to the main industry, persevere innovation, which is precisely the shortcoming of the essence of entrepreneurship.

Whether the entrepreneurial spirit can become the source of innovation determines whether the enterprise can become the main body of innovation. According to statistics, from seventeenth Century to 1970s, 160 main innovations have changed the human life (recognized by economists), and the company completed more than $80 \%$ of the total, while the multinational companies have $70 \%$ of the world's patent and invested $2 / 3$ of the global R \& D funds. [10]Technology innovation has become the normality of enterprise production and management, and technological innovation has greatly promoted the improvement of enterprise efficiency. From the point of the view of scientific and technological innovation, the role of technological progress in economic growth is very obvious. According to the 2014 China Science and Technology Statistics Yearbook, the contribution rate of scientific and technological progress to China's GDP growth has increased year by year, during 1998-2003, it was 39.7\%.During 2007-2012, and it reached to 52.2\%. Compared with this, Chinese enterprise investment in technological innovation is seriously insufficient, the national scale industrial enterprises, for example, R \& D funds accounted for the proportion of sales revenue were $1.7 \%, 1.76 \%, 1.84 \%$, $1.98 \%, 2.08 \%$ in $2009-2013$ years. It is visible that the Chinese enterprises investment in technology innovation is very limited. Although not all decisions are directly responsible for the enterprise, but all aspects of the production and operation of enterprises are affected by entrepreneurs, to a certain extent, the enterprise behavior is the behavior of entrepreneurs. Therefore, the lack of innovation, lack of R \& $\mathrm{D}$ funding and other short-sighted behavior is a reflection of the lack of entrepreneurship.

Cultural differences may be one of the reasons for the lack of innovation (such as the difference between eastern and Western cultures). Kim Jong-hoon (president of the laboratory of Baer) pointed out that the United States culture advocates innovation, tolerance and change, while the eastern culture respected all things to reach an agreement. But innovation is often generated under the collision of different views. In the current western business circles, the power to create a new industry or market lies in innovation, and this is accompanied by entrepreneur's innovative personality, as Grof (Intel CEO) said: "only the paranoid survives". Therefore, cultivating the innovative spirit of Chinese entrepreneurs, needs continuous progress of the social culture, foster innovation, change the concept of tolerance, create diversified values, and the formation of an inclusive entrepreneur "paranoid" social atmosphere.

\section{Abandon the rent-seeking consciousness}

The rent-seeking consciousness of entrepreneurs is that the entrepreneur tries to establish a good relationship with the government and other stakeholders to obtain the opportunity of rent-seeking. In China's real situation, there is a close relationship between the interests of many entrepreneurs and government officials at all levels. Innovation, especially technological innovation, needs the investment of a large number of people, money, material resources, and has a greater risk, compared to rent-seeking is easy and effective, resulting in the majority of entrepreneurs choose rent-seeking rather than innovation. This shows that the spirit of opportunism and rent-seeking consciousness is obvious in the current China entrepreneurship. Chinese enterprises mainly rely on "arbitrage" (that is not balanced, grasp the imbalance) instead of creating imbalance in value, arbitrage and rentseeking interests, the vast majority of entrepreneurs are often short-sighted strategy, quick success, the lack of investment in the future long term planning.

Under the new normality, the flow of government functions is an important way to get rid of the entrepreneur rent-seeking consciousness.[10]In addition to the cultural differences between the East and the west, another important reason for the lack of entrepreneurship in China is the 
drawbacks of the system and institutional arrangements. Innovation of the existing system and institutional arrangements to reduce the space of opportunism and rentseeking, innovation and entrepreneurship will be effectively released. For a long time, due to the impact of the planned economy, the spirit of fair, rule of law and the characteristics of the market is difficult to form, which is the fundamental reason for the stagnation of entrepreneurship.[11]Under the new economic normal, adjust the leading role of government power in the allocation of resources, play the basic role of the market in the allocation of resources, and create a good market environment for enterprises is the power source to promote entrepreneurship innovation and enterprising.

\section{Rebuilding the spirit of entrepreneur contract}

For a long time, the business community has been plagued by the low trust business environment and the lack of business integrity, which is also the quality problems of China's economic operation, the reason is the loss of entrepreneurial spirit of the contract.

The spirit of contract is the pillar and core of modern commercial civilization, which is the foundation of market economy, which is composed of four parts: the freedom of contract, the equality of the parties, the contract and contract remedies. Adhering to the spirit of the product contract is the core of the spirit of the contract spirit of the enterprise, which requires enterprises to eliminate fake and shoddy products. The lack of the spirit of the entrepreneur contract causes the deterioration of the market environment and reduces the trust of the transaction relationship. On the one hand, the increase of transaction cost and social cost, it is difficult to establish a trust relationship between enterprises and consumers; on the other hand, it restricts the enterprise brand to high-end leap, caused by special China enterprises "middle income trap" (i.e. when the independent brand and strive to get rid of the lowend positioning, but the enterprises and the whole industry with negative evaluation Chinese manufacturing). [12]This situation leads to the survival of the enterprise brand space and the growth of space curing, the difficulty of the brand to the higher end increase, and the intangible loss of the enterprise is far greater than the benefits of immoral behavior. Therefore, reshaping the spirit of entrepreneur contract, improving the quality of products, and developing national brand have become the most urgent task for the development of Chinese enterprises under the new normality condition.

\section{CONCLUSION}

The new economic normality has put forward new requirements for Chinese entrepreneurs, also created a historic opportunity for entrepreneurs to realize the ambition. The majority of entrepreneurs should have a profound understanding of the new economic normality, actively adapt to the new economic norm, enhance the sense of mission and responsibility, have the spirit of innovation, make efforts to promote innovation and development, ensure steady economic growth, and promote the sustained and healthy development of China's enterprises.

\section{REFERENCES}

[1] Richard Cantillon, Commercial introduction. Beijing: the Commercial Press, 2011,pp.70-71. (In Chinese)

[2] Joseph Alois Schumpete,Economic development theory.Beijing:China Machine Press, 2010,pp.178-182. (In Chinese)

[3] Alfred Marshall, Principles of economics.Beijing:People's daily press, 2009,pp.38-40. (In Chinese)

[4] Feng Sining, Li Zhi, Inheritance of family business from the perspective of entrepreneurship, Journal of Fujian Commercial College, Chapter 6, 2013,pp.34-35. (In Chinese)

[5] Wang Jingjing, Du Jingjing, Xia fan,An Empirical Study on the difference of social entrepreneurship and its relationship with the growth of enterprises, Journal of Lanzhou University of Finance and Economics, Chapter 6,2014,pp.64-66. (In Chinese)

[6] Zhang Weiying, Sheng bin,Entrepreneur:the king of economic growth.Beijing:Sanlian bookstore, 2004. (In Chinese)

[7] Wang Cheng,Entrepreneur in the transformation of growth pattern and its mechanism ,economic research, Chapter 5,1999,pp.75-81. (In Chinese)

[8] Cai Fang, How to Chinese economic growth to TFP driven,China social science, Chapter 1,2013 ,pp. 56-71,206. (In Chinese)

[9] Wang Zhongyu,Vigorously promote entrepreneurship to promote innovation and development of enterprises under the new normal ,enterprise management, Chapter 7,2015,pp.6-9. (In Chinese)

[10] "The power of the company" program group, The strength of the company. Taiyuan: Shanxi Education Press, 2010,pp.202-203. (In Chinese)

[11] Yang Jing,The pursuit of entrepreneurial spirit in the post Jobs era: a discussion on the differences between Chinese and foreign entrepreneurs from the cultural background, Chapter 13,2012,p.580. (In Chinese)

[12] Yang lijun, Reshaping of Entrepreneur Spirit under New Economic Normal State, Journal of Henan University of Science and Technology (social science edition),Chapter 6,2015, pp.86-89. (In Chinese) 